\title{
Two Quick Ways to Improve Teaching: Learning Objectives and Plus/Delta Forms
}

\author{
David C. Miller \\ Department of Chemical Engineering \\ Rose-Hulman Institute of Technology
}

\section{Introduction}

A new engineering educator seeking to become a better teacher and to improve classroom interaction can easily become overwhelmed by the large number of approaches that have been described in the literature. Although some of these, such as problem-based learning and active learning, have been shown to significantly enhance student learning and retention, they are perhaps not the best approaches to adopt during the first few years as a faculty member. Compared with more traditional teaching techniques, these approaches typically require a significant time commitment from the instructor, and they are usually initially met with student resistance and hostility, resulting in negative teaching evaluations. A new faculty member may be better served by initially adopting simpler techniques that require less additional time and result in immediately higher teaching evaluations. Making use of detailed learning objectives and weekly plus/delta forms are two quick ways to potentially improve student learning and course evaluations.

\section{Learning Objectives}

As described by several authors [1-4], detailed learning objectives are a set of specific tasks that the students are expected to be able to accomplish. These can be communicated as daily objectives, weekly objectives or objectives for an exam. These objectives differ from course objectives by being specifically geared toward actions that the student should be able to perform in order to demonstrate their proficiency.

Learning objectives help students understand exactly what is expected of them, so they know what to focus on when studying. When an instructor bases an exam on these learning objectives and promises not to ask any questions outside the scope of these objectives, students perceive the instructor as being fairer. Thus, teaching evaluations may improve since the instructor is not perceived as trying to trick the students.

Since the students know what is expected of them, they can make more effective use of their study time. In fact, many students will go through the list of objectives and make sure they can perform each task. This may result in better overall student learning and improved student performance on exams. 
Furthermore, learning objectives benefit course organization because they help focus material and the allocation of class time to correspond with those topics that are considered important enough to have learning objectives associated with them. The initial time invested to develop learning objectives for a course or block of material is counterbalanced by reducing the amount of time required to prepare exams because the types of questions that can be asked have already been identified.

An initial set of learning objectives for one third of a course can be prepared in about an hour. In general, the instructor should review course material and assignments in order to determine what the students should be able to do with this material and how the student could demonstrate understanding. When writing learning objectives, words such as know, learn, appreciate, and understand should be avoided since they cannot be directly observed. Instead, words such as list, explain, describe, calculate, determine, compare, design, and recommend should be used. Stice [5] suggests that the following relationship between the six different levels of Blooms taxonomy [6] and various verbs useful for creating learning objectives.

Table 1. Relationship between Bloom's Cognitive Level and Learning Objective Verbs.

\begin{tabular}{|c|l|l|}
\hline $\begin{array}{c}\text { Bloom's } \\
\text { Cognitive } \\
\text { Level }\end{array}$ & Cognitive Domain & Typical Verbs Describing Measurable Behavior \\
\hline 1. & Knowledge & List, recite \\
\hline 2. & Comprehension & Explain, paraphrase, describe \\
\hline 3. & Application & Calculate, solve, determine, apply \\
\hline 4. & Analysis & Compare, contrast, classify, categorize, derive, model \\
\hline 5. & Synthesis & $\begin{array}{l}\text { Create, invent, predict, construct, design, imagine, } \\
\text { improve, produce, propose }\end{array}$ \\
\hline 6. & Evaluation & $\begin{array}{l}\text { Judge, select, decide, critique, justify, verify, debate, } \\
\text { assess, recommend, argue }\end{array}$ \\
\hline
\end{tabular}

The following are some of the learning objectives from a senior-level chemical engineering design course.

1. Create a Profit and Loss Statement for any process, calculating all the elements related to revenue and/or expense.

2. Explain the meaning of the terms in a P\&L Statement.

3. Calculate working capital based on the reserves, receivables, payables, etc. described in the text.

4. Recommend (from an economic standpoint) the best investment out of various options.

5. Use EAOC and/or the capitalized cost method to evaluate alternatives with different lives.

6. Determine the minimum utilities required to heat and cool a given set of process streams.

7. Determine heat exchanger network configuration to achieve a minimum utilities (i.e., stream matches, temperatures and duties). 


\section{Plus/Delta}

Plus/delta $(+/ \Delta)$ forms provide a way for students to give anonymous feedback to the instructor prior to the end of the course. This allows the instructor to demonstrate that he or she cares about student learning. In addition, it allows the instructor to avoid the problem of not finding out until the end of the course that student learning could have been improved by making some small adjustments. Students benefit from having an outlet to voice their opinions and have a voice in the way class is run. As one student recently commented, this allows the current group of students to benefit from suggestions instead of just future classes as occurs when the only feedback mechanism is an evaluation form at the end of the term.

To implement plus/delta's in class, the instructor should prepare plus/delta forms. An example plus/delta is shown in Figure 1. These forms are typically one third of a page and prepared by making a number of copies and cutting the sheets in thirds. It typically takes no more than 15 minutes to prepare a sufficient number for several weeks of class. The forms should then be distributed at the beginning of class, one day a week, typically on Friday.

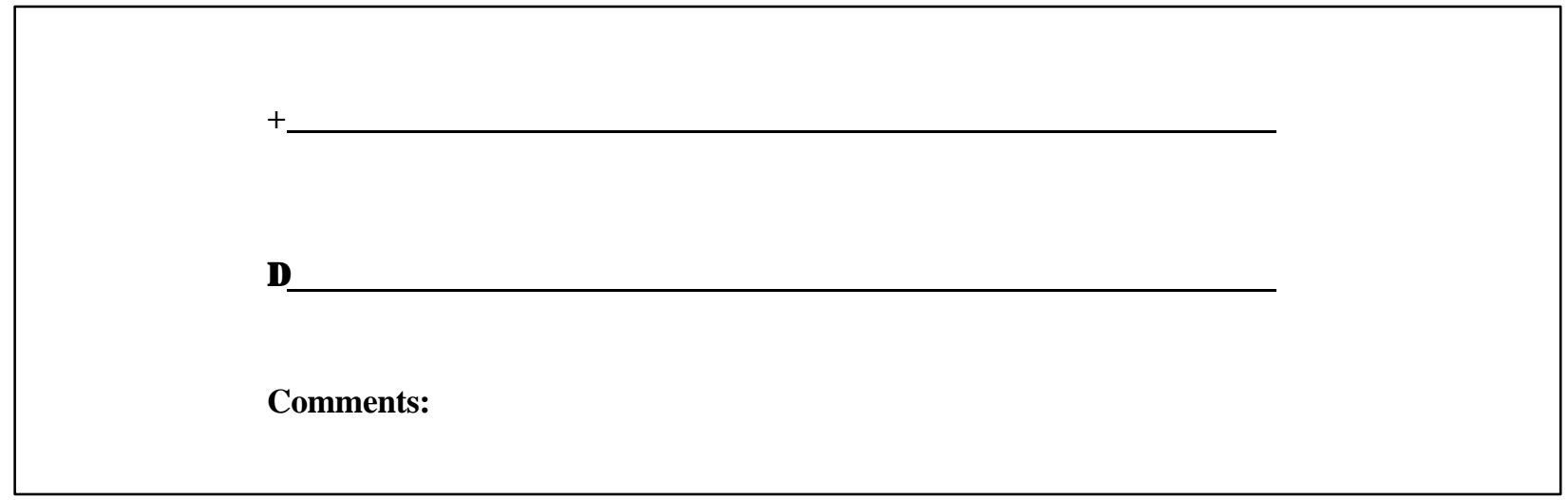

Figure 1. Example of a Plus/Delta form.

The format of the form is such that students can give a positive comment (plus) about an aspect of the course that they found helpful or liked. An example might be distributing learning objectives prior to an exam. The delta portion of the form gives the students the opportunity to suggest something be changed or indicate a topic that is not clear. The students fill out the forms at some point during the class. At the end of the class period, the students deposit the forms at the front of the room. This requires very little actual class time.

After class, the instructor should review the comments and consider whether suggested changes are appropriate and especially note aspects of the course that have been perceived as positive, so that they can be continued. The comments can typically be reviewed and considered in about 15 minutes for a class of 50 students. In general, many of the comments will reflect common ideas and concerns. These provide the strongest basis for considering things to change in the course. For example, in some of my recent classes, many students indicated that they wanted the 
learning objectives earlier than I was providing them, so I worked to have them ready a week prior to the exam. Other students indicated that they really appreciated the handouts that I provided, so I continued to provide those when appropriate. Other comments have addressed the format of the handouts. At times, the class may indicate conflicting ideas such as half the class indicating the pace is too slow and half indicating that the pace is too fast, which provide an opportunity to discuss the conflict with the class so they understand that I am trying to balance a diverse set of needs. Occasionally, a few students will make silly suggestions, such as getting a horn to announce "half time" or a pet gerbil to serve as class mascot. These types of comments, if read in class, at least generate a few laughs from the students and help to foster a positive atmosphere in class.

At the beginning of the next class day, I will take the first five minutes of class to read some of the responses verbatim and summarize the comments. Then, I will indicate things about the course that will change and things that will remain the same based on their feedback. Finally, I will address issues that are outside of my control, such as the fact that the course meets at 8 AM. Almost every student seems to really appreciate the plus/delta forms, and most indicate so on their final course evaluations.

\section{Conclusions}

Preparing detailed learning objectives and providing these to students prior to exams allows students to better understand and meet the expectations of the instructor, resulting in the instructor being perceived as more fair. Plus/delta forms provide another simple method to improve classroom interaction by allowing the students to have some input into how the class is taught. Both of these ideas result in a more productive learning environment and can be implemented without radically altering the content or format of the course.

\section{References}

1. R.F. Mager, Preparing Instructional Objectives. Fearon Publishing. 1962.

2. J.E. Stice, “A First Step Toward Improved Teaching”, Engineering Education. 66, 394-398. 1976

3. R.M. Felder \& R. Brent, “Objectively Speaking”, Chemical Engineering Education, 31, 178-179. 1997.

4. R.M. Felder \& R. Brent, "How to Improve Teaching Quality", Quality Management Journal, 6, 9-21. 1999.

5. J.E. Stice, Handout from ChE Summer School Workshop, Boulder, CO, July 2002.

6. B.S. Bloom, Taxonomy of educational objectives. 1. Cognitive domain. New York, Longman, 1984.

\section{Biographical information}

DAVID C. MILLER

David C. Miller is an Assistant Professor of Chemical Engineering at Rose-Hulman Institute of Technology. Dr. Miller has previously taught at Michigan Technological University and The Ohio State University. He received his B.S. degree from Rose-Hulman Institute of Technology, M.S. from University of Illinois, Urbana-Champaign, and Ph.D. from The Ohio State University. 